\title{
Farming deaths - an ongoing problem
}

\author{
Roger W. Byard ${ }^{1}$
}

Accepted: 1 January 2017 /Published online: 14 January 2017

(C) Springer Science+Business Media New York 2017

Farming looks mighty easy when your plow is a pencil and you're a thousand miles from a corn field.

Dwight D. Eisenhower (1890-1969)

The case reported by Peyron and Baccino of a farmer who was decapitated when his clothing became caught in the drive shaft of a tractor [1] draws stark attention to the dangers still inherent in farming and agricultural work. In many countries farming is one of the most dangerous of occupations, with Australian data showing that of the 195 workers killed in that country in 2015,53 were involved in agriculture, forestry or fishing (27\%), 44 in transport (22\%), 29 in construction (15\%) and only 11 in mining (6\%) [2]. Reasons for the high morbidity and mortality rates on farms relate to economic and cropping pressures and include working during all weather conditions, working for extended hours during peak seasons, not using personal protection equipment, and using old and possibly poorly-maintained equipment [3]. Thus, victims of agricultural accidents are regularly presented for medicolegal assessments in morgues around the world [3-7]. Alcohol has been detected in between 9 to $37.2 \%$ of victims $[3,5]$.

In an eight-year national study from 2003 to 2011 in Australia, the 365 workers who died on farms represented $17 \%$ of all worker fatalities [8]. The types of fatal incidents involved vehicles (39\%), impact with a moving object (17\%), entrapment by equipment/machinery (11\%), impact by falling

Roger W. Byard

roger.byard@sa.gov.au

1 Discipline of Anatomy and Pathology, Level 3 Medical School North Building, The University of Adelaide, Frome Road,

Adelaide, SA 5005, Australia objects (8\%), falls (7\%), animals (6\%), electrocution (6\%) and miscellaneous causes [8]. The vehicle deaths were predominantly due to tractors, with other deaths involving aircraft, light vehicles and quad bikes [8]. Injuries from non-fatal accidents are more likely to result from lifting, handling or carrying, falling from heights and animal actions [6].

Fatal injuries that occur tend to be severe with limb amputations, evisceration, crushing and decapitation [4]. A study of occupational traumatic brain injury in the United States showed that over half were reported from the construction, transportation and agriculture/forestry/fishing industries. Death rates were 15 times higher in males, with the highest rates of traumatic brain injury deaths occurring in males aged 65 years and older [9]. In Australia farm fatalities tend to occur mainly in white males, who account for $67 \%$ of workers but $92 \%$ of deaths and $85 \%$ of hospital admissions [8]. A similar finding was reported from an 11-year retrospective study of tractor-related deaths from Virginia, United States where $98 \%$ of the victims were male and $91 \%$ were white. The average age was 60 years with rollovers accounting for $54 \%$ of cases, the majority $(60 \%)$ of these occurring on hills or inclines [5]. This is predisposed to by the narrow wheel base of tractors in combination with their relatively high center of gravity [3].

Using a tractor for logging activities was found to be particularly high risk [5]. The risk of non-fatal injuries was also found to be highest in forestry workers in a study from England and Wales, and also in those who had recently started agricultural work [6]. An increased risk of accidents has also been associated with the use of illegal seasonal workers who have had no safety training [3]. Other issues with temporary workers include their lack of experience, poor general training and often worse working conditions [10]. 
Other severe injuries, as occurred in the case reported by Peyron and Baccino [1], may result from entanglement of clothing in power take-off drive lines. These are metal shafts that rotate rapidly at the back of tractors powering other equipment. They often do not have safety shields and may cause rapid death from avulsion of limbs, or from crushing the body and head [4]. In a study from Konya in Turkey power take-off entanglements were responsible for $5.8 \%$ of the deaths [7].

Farming also has a higher rate of animal-related deaths than most other occupations and this may involve both domesticated and wild species. Large animals such as cows, buffalo and horses may cause severe injuries, and death may result from being kicked, crushed, gored or stomped on [11, 12]. The most significant injuries involve the head and face, and then the upper torso. Pigs may cause significant injuries with their tusks, or from biting, and sheep have been known to cause lethal blunt force injuries from charging handlers $[11,13]$. An unusual death caused by a sheep was severing of the major neck vessels by electric clippers that had been knocked out of the shearers hand [14]. Farm workers are also exposed to dangers from snake and bee envenomation which may induce fatal anaphylaxis [15].

Asphyxiation accounted for $7 \%$ of deaths in a British study [16] and may result from entrapment by machinery or tractors or from an unstable but heavy object such as a hay bale. Hay baling is a particularly agricultural activity that may result in death from a variety of mechanisms [17, 18]. Other causes of asphyxiation include exposure to methane in storage sheds or wheat silos, or to carbon monoxide from using faulty equipment in confined spaces [3]. A similar risk of the latter has been reported in the fishing industry [19]. Entrapment in wheat within a silo may also result in death from a combination of suffocation and chest compression. Other deaths have been caused by exposure to extremes of temperature, to insecticides and to the effects of brushfires (bushfires) [20]. Given the average age of the decedents, the possibility of significant underlying organic disease should be considered. For example, cardio- and cerebrovascular disease was responsible for $20 \%$ of deaths in one series of farm-related fatalities [3]. With increasing economic hardships in rural communities and the ready availability of firearms, suicide is also another significant category of rural death in a number of countries [21,22].

Safe Work Australia classified deaths of non-workers on farms as "bystander deaths". In their eight year study there were 41 of these types of deaths compared to the 365 that involved workers. Of note, 35 of these victims $(85 \%)$ were children under the age of 10 years. Drowning accounted for the highest number of deaths with 13 cases, 10 of whom were children [8]. Children are particularly vulnerable to injury and death on farms due to the hazards resulting from the unique blend of home and industrial environments. For example, while only $2 \%$ of children in the United States live on farms, the number of fatalities from farm machines almost equals deaths from falls or poisoning in the home [4, 23]. Problems arise from tractor run-overs, drowning in waterways or dams, suffocation in wheat silos, and unsupervised access to machinery [24-26]. There is an age-related vulnerability, with injuries from vehicle run-overs, animal kicks and falls tending to involve younger children. Visitors to farms may be at even higher risk. Older children are more likely to get hurt when using equipment without proper supervision or from falling off horses or motor cycles [27-29]. Involvement of all family members in the full range of farm activities also increases the chances of injury and death in the young [3, 30].

As Dwight Eisenhower pointed out so pithily, although farming may seem an easy occupation when it is observed from a safe distance, it remains a potentially dangerous activity in many countries for a wide variety of economic, cultural and geographic reasons. Injuries can be severe and mechanisms of death can be quite diverse. The medicolegal issues may be complex if issues of insurance or adherence to work standards are being investigated.

\section{References}

1. Peyron P-A, Baccino E. A case of accidental decapitation in a farm worker. Forensic Sci Med Pathol. (In press).

2. Worker fatalities. Safe Work Australia. http://www. safeworkaustralia.gov.au/sites/swa/statistics/workrelatedfatalities/pages/worker-fatalities. Accessed 30 Dec 2016.

3. Rorat M, Thannhauser A, Jurek T. Analysis of injuries and causes of death in fatal farm-related incidents in lower Silesia, Poland. Ann Agri Environ Med. 2015;22:271-4.

4. Byard RW, Gilbert J, James R, Lipsett J. Pathological features of farm and tractor-related fatalities in children. Am J Forensic Med Pathol. 1999;20:73-7.

5. Fulcher J, Noller A, Kay D. Farming tractor fatalities in Virginia. An 11-year retrospective review. Am J Forensic Med Pathol. 2012;33:377-81.

6. Solomon C, Poole J, Plamer KT, Coggan D. Non-fatal occupational injuries in British agriculture. Occup Environ Med. 2007;64:150-4.

7. Dogon KH, Demirci S, Sunam GS, Deniz I, Gunaydin G. Evaluation of farm tractor-related fatalities. Am J Forensic Med Pathol. 2010;31:64-8.

8. Work-related injuries and fatalities on Australian farms. Safe Work Australia. http://www.safeworkaustralia.gov. au/sites/SWA/about/Publications/Documents/759/Work-relatedinjuries-fatalities-farms.pdf. Accessed 30 Dec 2016.

9. Tiesman HM, Konda S, Bell JL. The epidemiology of fatal occupational traumatic brain injury in the US. Am J Prev Med. 2011;41: 61-7.

10. Villanueva V, Garcia AM. Individual and occupational factors related to fatal occupational injuries: a case-control study. Accid Anal Prev. 2011;43:123-7.

11. Bury D, Langlois NEI, Byard RW. Animal-related fatalities part I: characteristic autopsy findings and variable causes of death associated with blunt and sharp trauma. J Forensic Sci. 2012;57:370-4.

12. Byard RW. Causes and mechanisms of death in fatal water buffalo attacks. J Forensic Sci. (In press).

13. Škavić P, Šprem N, Kostelić A. Fatal injury caused by a ram (Ovis Aries) attack. J Forensic Sci. 2015;60:1380-2. 
14. Irandoust S, Heath K, Byard RW. Sheep shearing and sudden death. J Forensic Legal Med. 2013;20:944-6.

15. Bury D, Langlois NEI, Byard RW. Animal-related fatalities part II: characteristic autopsy findings and variable causes of death associated with envenomation, poisoning, anaphylaxis, asphyxiation and sepsis. J Forensic Sci. 2012;57:375-80.

16. Solomon C. Accidental injuries in agriculture in the UK. Occup Med. 2002;52:461-6.

17. Byard RW. The brassiere 'sign' - a distinctive marker in crush asphyxia. J Clin Forensic Med. 2005;12:316-9.

18. Charlwood C, Byard RW. Potential dangers of hay bailing. J Forensic Legal Med. 2014;21:56-8.

19. Byard RW. Commercial fishing industry deaths - forensic issues. $\mathrm{J}$ Forensic Legal Med. 2013;20:129-32.

20. Byard RW, Gilbert JD, Kostakis C, Heath K. Circumstances of death and diagnostic difficulties in brushfire fatalities. J Forensic Sci. 2012;57:969-72.

21. Fraser CE, Smith KB, Judd F, Humphreys JS, Fragar LJ, Henderson A. Farming and mental health problems and mental illness. Int J Soc Psychiatry. 2005;51:340-9.
22. Bossard C, Santin G, Guseva CI. Suicide amongst farmers in France: occupational factors and recent trends. J Agromed. 2016;21:310-5.

23. Dunn KA, Runyan CW. Deaths at work among children and adolescents. Am J Dis Child. 1993;147:1044-7.

24. Byard RW, Gilbert J, Lipsett J, James RA. Farm and tractor-related fatalities in children in South Australia. J Paediatr Child Health. 1998;34:139-41.

25. Mandryk J, Harrison J. Work-related deaths of children and adolescents in Australia, 1982 to 1984. Aust J Pub Health. 1995;19:46-9.

26. Salmi LR, Weiss HB, Peterson PL, et al. Fatal farm injuries among young children. Pediatrics. 1989;83:267-71.

27. Byard RW. Accidental childhood death and the role of the pathologist. Pediatr Develop Pathol. 2000;3:405-18.

28. Cameron D, Bishop C, Sibert JR. Farm accidents in children. Brit Med J. 1992;305:23-5.

29. Holland AJA, Roy GT, Goh V, et al. Horse-related injuries in children. Med J Aust. 2001;175:609-12.

30. Swanson JA, Sachs MI, Dahlgren KA, Tinguely SJ. Accidental farm injuries in children. Am J Dis Child. 1987;141:1276-9. 